Article

\title{
Preparation of Calibration Standards of N1-H Paralytic Shellfish Toxin Analogues by Large-Scale Culture of Cyanobacterium Anabaena circinalis (TA04)
}

\section{Ryuichi Watanabe ${ }^{1, *}$, Toshiyuki Suzuki ${ }^{1}$ and Yasukatsu Oshima ${ }^{2}$}

1 National Research Institute of Fisheries Science, 2-12-4 Fukuura, Kanazawa-ku, Yokohama 236-8648, Japan; E-Mail: tsuzuki@affrc.go.jp

2 School of Marine Biosciences, Kitasato University, 160-4 Okirai-uto, Sanriku-cho, Ofunato 022-0101, Japan; E-Mail: oshima.y@kitasato-u.ac.jp

* Author to whom correspondence should be addressed; E-Mail: rwatanabe @ affrc.go.jp; Tel.: +81-45-788-7630; Fax: +81-45-788-5001.

Received: 9 February 2011; in revised form: 3 March 2011 / Accepted: 18 March 2011 / Published: 22 March 2011

\begin{abstract}
Mouse bioassay is the official testing method to quantify paralytic shellfish toxins (PSTs) in bivalves. A number of alternative analytical methods have been reported. Some methods have been evaluated by a single laboratory validation. Among the different types of methods, chemical analyses are capable of identifying and quantifying the toxins, however a shortage of the necessary calibration standards hampers implementation of the chemical analyses in routine monitoring of PSTs in bivalves. In our present study, we studied preparation of major PST analogues as calibrants by large-scale cultivation of toxic freshwater cyanobacteria Anabaena circinalis TA04. The cells were steadily grown in $10 \mathrm{~L}$ bottle for 28 days. The primary $\mathrm{N} 1-\mathrm{H}$ toxins, $\mathrm{C} 1 / \mathrm{C} 2$, were produced at a concentration of $1.3 \pm 0.1 \mu \mathrm{mol} / \mathrm{L}$. The intracellular and extracellular toxins occupied $80 \%$ and $20 \%$, respectively. Over $220 \mu \mathrm{mol}$ of the toxins was obtained from approximately $200 \mathrm{~L}$ of the culture over six months, demonstrating that it is sufficient to prepare saxitoxin analogues. The toxins were chemically converted to six N1-H analogues. Preparation of the analogues was carried out at relatively high yields (50-90\%). The results indicate that our preparation method is useful to produce N1-H toxins. In our present study, detailed conditions for preparation of one of the rare $\mathrm{N} 1-\mathrm{H}$ analogues, gonyautoxin-5, were investigated.
\end{abstract}

Keywords: cyanobacteria; Anabaena circinalis; paralytic shellfish toxin; saxitoxin; chemical derivatization; standard 


\section{Introduction}

Paralytic shellfish toxins (PSTs), one of the most potent groups of neurotoxins in marine biotoxins, are produced by toxic marine dinoflagellates and freshwater cyanobacteria. Around 30 analogues have been reported (Figure 1). Some of these analogues are metabolic products of algae-derived toxins in shellfish [1]. Approximately 20 analogues are found to show a wide range of toxicity [2]. Natural and cultivated shellfish are contaminated with PSTs by feeding on toxin-producing algae, and are a potential cause of paralytic shellfish poisoning (PSP) to humans. Although mouse bioassay (MBA), which is the official testing method to determine shellfish toxicity in many countries, is effective in protecting the consumers from PSP, alternative methods are required due to some drawbacks including accuracy, reproducibility and ethical concerns [3].

A number of alternative analytical methods have been developed to date. Some have been evaluated by a single laboratory validation [4,5]. Among different types of methods, high performance liquid chromatography fluorescent detection (HPLC-FD) is one of the reliable methods to identify and quantify individual toxins. It is reported that the toxicity obtained by HPLC-FD is usually consistent with the total toxicity of MBA by measuring the major toxins $\mathrm{C} 1-4$, gonyautoxin (GTX) 1-6, decarbamoylgonyautoxin (dcGTX) 2 and dcGTX3, neosaxitoxin (neoSTX), decarbamoylsaxitoxin (dcSTX) and saxitoxin (STX) [2]. However, although the calibration standards are commercially available from the National Research Council Canada (NRC), shortage of the calibration standards has hampered implementation of HPLC-FD in routine monitoring of PSTs in bivalves.

In preparation of high amount of the calibration standards, selection of natural source materials is important. Shellfish with a high level of toxicity [6,7] are one of the important natural sources but this source has hardly been obtainable in Japan over the last decade due to very low levels of toxicity (at most 10-50 MU/g). Therefore, some toxic dinoflagellates such as Alexandrium excavatum [8] and A. tamarense [9] are used as appropriate source materials in terms of stable toxin source materials. Some toxin-producing cyanobacteria such as Anabaena circinalis and Aphanizomenon flos-aquae would also be ideal source materials in toxin production and cell growth.

Because primary toxins produced by toxic algae are insufficient to account for the complicated PST analogues in shellfish, chemical conversion of the primary toxins to other analogues is used to produce a variety of toxins. Some chemical or enzymatic reactions were summarized for each substituent moiety; C11, C13 and N1 positions [10].

Figure 1. Structures of paralytic shellfish toxins.

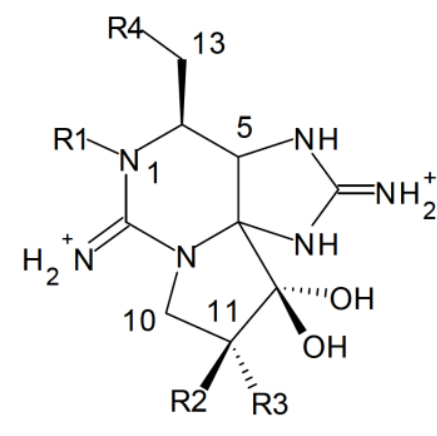

\begin{tabular}{|c|c|c|c|c|c|}
\hline $\mathbf{R} 1$ & $\mathbf{R 2}$ & $\mathbf{R 3}$ & R4: $-\mathrm{OCONH}_{2}$ & $-\mathrm{OCONHSO}_{3}^{-}$ & $-\mathrm{OH}$ \\
\hline $\mathrm{H}$ & $\mathrm{H}$ & $\mathrm{H}$ & STX & GTX5 & dcSTX \\
\hline $\mathrm{OH}$ & $\mathrm{H}$ & $\mathrm{H}$ & neoSTX & GTX6 & dcneoSTX \\
\hline $\mathrm{OH}$ & $\mathrm{H}$ & $\mathrm{OSO}_{3}^{-}$ & GTX1 & $\mathrm{C} 3$ & dcGTX1 \\
\hline $\mathrm{H}$ & $\mathrm{H}$ & $\mathrm{OSO}_{3}^{-}$ & GTX2 & $\mathrm{C} 1$ & dcGTX2 \\
\hline $\mathrm{H}$ & $\mathrm{OSO}_{3}^{-}$ & $\mathrm{H}$ & GTX3 & $\mathrm{C} 2$ & dcGTX3 \\
\hline $\mathrm{OH}$ & $\mathrm{OSO}_{3}^{-}$ & $\mathrm{H}$ & GTX4 & $\mathrm{C} 4$ & dcGTX4 \\
\hline
\end{tabular}


Among the known toxins, $\mathrm{N}$-sulfocarbamoyl gonyautoxins, $\mathrm{C} 1 / \mathrm{C} 2$, are useful to produce other $\mathrm{N} 1-\mathrm{H}$ analogues by chemically removing the substituent moieties. Although adequate conditions for conversion of $\mathrm{C} 1 / \mathrm{C} 2$ to dcGTX2/dcGTX3, dcSTX, and GTX2/GTX3 were reported in previous papers [11,12], detailed investigation of chemical conversion of other analogues (e.g., GTX5) that are more dominant toxins in shellfish, has not been reported yet. In this paper, we focused on large-scale cultivation of the cyanobacteria A. circinalis to prepare a variety of $\mathrm{N} 1-\mathrm{H}$ analogues from $\mathrm{C} 1 / \mathrm{C} 2$ by chemical conversion.

\section{Results and Discussion}

\subsection{Large-Scale Culture of Cyanobacteria A. Circinalis (TA04)}

The cultured A. circinalis (strain TA04) has been maintained in modified C medium since 1996 [13]. The culture showed dark-green color in mid-stationary phase, and turned to chrome yellow color in late-stationary phase. The biomass and the toxin concentration also increased in the exponential growth phase, followed by the short induction growth phase ( $\sim 7$ days, Figure 2$)$. As the toxin concentration declined when the culture reached the late-stationary phase, the cells were harvested at 28 days. The cultured cyanobacteria produced C1/C2 (70-90\%) as the dominant toxins. Although GTX2/GTX3 and dcGTX2/dcGTX3 (5-15\% each) were produced as the minor toxins, N1-hydroxylated toxins such as GTX1/GTX4 were not found in the harvested culture. The toxin components determined in our present study were different from those obtained in our previous study [13].

Figure 2. Growth curve (A) and toxin production (B) in a large-scale culture of A. circinalis. (A) Fluorescent intensity shows the average level of chlorophyll $a$ in cells $(n=3)$; (B) Only C1/C2 produced by the cells were analyzed by high performance liquid chromatography fluorescent detection (HPLC-FD). Solid line shows total toxin concentration of $\mathrm{C} 1 / \mathrm{C} 2$ in culture. Dashed line shows intracellular toxin concentration of $\mathrm{C} 1 / \mathrm{C} 2$. The difference corresponds to the extracellular toxin concentration.
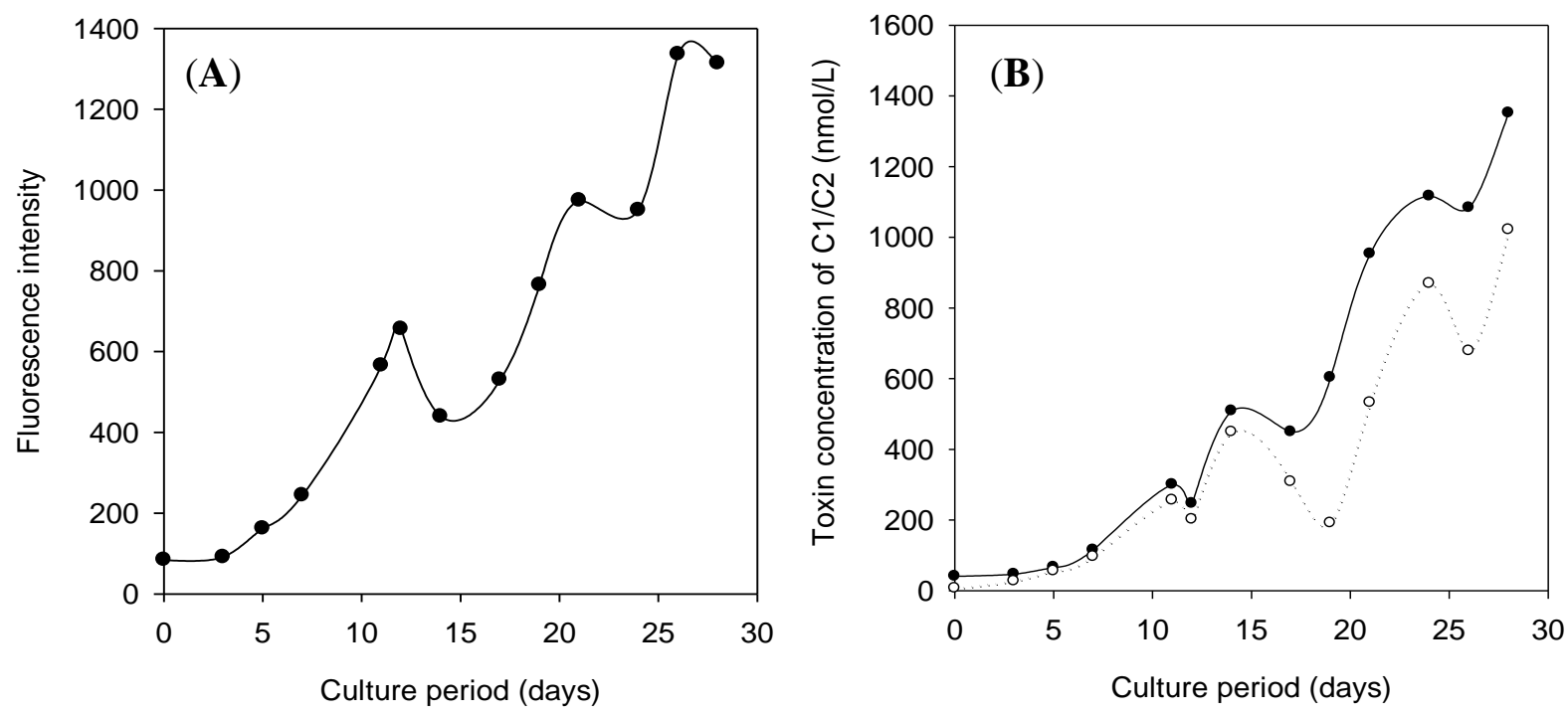
This difference is probably caused by physiological natural changes due to the long-term successive culture over 15 years and the change of culture medium. On the other hand, the $\alpha / \beta$-epimer ratio of $\mathrm{C}$-toxins was 1.1, which was close to previous data [14]. The toxin production of $\mathrm{C} 1 / \mathrm{C} 2$ in large-scale culture was $1.3 \pm 0.1 \mu \mathrm{mol} / \mathrm{L}$ culture $(7 \% \mathrm{RSD}, n=3)$ at 28 days. This value was somewhat lower than that found in our previous study $(1.8-2.0 \mu \mathrm{mol} / \mathrm{L}$ culture). Approximately $80 \%$ of the total toxins were found inside the cells. Our result was similar to that obtained in another strain, MB06 [14], which was collected in the same location as our material strain, TA04, in the ratio of epimers and intra-/extracellular toxin in $1.2 \mathrm{~L}$ small scale culture, whereas the cell growth of strain TA04 was slower than strain MB06.

The cyanobacteria were cultured under several modified conditions of Fitzgerald medium toward efficient toxin production. The biomass and toxin production for 28 days were investigated in each condition (Table 1). As a result, the concentration of nitrate and phosphate hardly affected the toxin production and biomass of the cyanobacteria. Two different inoculation volumes were determined to shorten the culture period, but the cell growth and the toxin production were the same as those of the control. In PST biosynthesis of cyanobacteria, the precursors such as arginine and $S$-adenosylmethionine were identified by the cultivation with stable isotopes [12] and a hypothetical pathway was proposed. The in vitro experiments for PST biosynthesis suggested that pyridoxal phosphate (PLP)-dependent enzymes were strongly involved in PST biosynthesis [15]. Therefore, the toxin production in the cell was investigated in vivo by adding a common cofactor, PLP, to the medium. Our study showed PLP hardly affected both cell growth and toxin production in our culture. PLP could be insufficiently incorporated into cells to be available to enzymes.

Table 1. Biomass and toxin production of $\mathrm{C} 1 / \mathrm{C} 2$ at 28 days of $A$. circinalis under modified condition of Fitzgerald medium.

\begin{tabular}{|c|c|c|c|c|c|c|}
\hline \multirow[b]{2}{*}{ Entry } & \multirow[b]{2}{*}{ Parameters } & & \multirow[b]{2}{*}{ Biomass } & \multicolumn{3}{|c|}{ Toxin concentration of $\mathrm{C} 1 / \mathrm{C} 2(\mu \mathrm{mol} / \mathrm{L})$} \\
\hline & & & & Total & $\begin{array}{c}\text { Intracellular } \\
(\%)\end{array}$ & $\begin{array}{c}\text { Extracellular } \\
(\%)\end{array}$ \\
\hline & Control & & 2300 & 1.39 & 80 & 20 \\
\hline 1 & $\mathrm{NaNO}_{3}$ & $0 \mathrm{mM}$ & 400 & 0.82 & 75 & 25 \\
\hline 2 & & $2.9 \mathrm{mM}$ & 1200 & 1.26 & 86 & 14 \\
\hline 3 & & $11.6 \mathrm{mM}$ & 1600 & 1.03 & 84 & 16 \\
\hline 4 & $\mathrm{~K}_{2} \mathrm{HPO}_{4}$ & $0.14 \mathrm{mM}$ & 1600 & 1.43 & 86 & 14 \\
\hline 5 & & $0.54 \mathrm{mM}$ & 2000 & 1.49 & 84 & 16 \\
\hline 6 & Inoculation & $0.5 \mathrm{~L}$ & 2000 & 1.36 & 77 & 23 \\
\hline 7 & & $2 \mathrm{~L}$ & 2500 & 1.05 & 84 & 16 \\
\hline 8 & Pyridoxal phosphate & $10 \mu \mathrm{M}$ & 2500 & 1.36 & 58 & 42 \\
\hline 9 & Glycerophosphate $\mathrm{Na}$ & $10 \mu \mathrm{M}$ & 3100 & 1.89 & 55 & 45 \\
\hline 10 & & $100 \mu \mathrm{M}$ & 2300 & 1.33 & 59 & 41 \\
\hline \multirow[t]{2}{*}{11} & Bicine & $0.6 \mathrm{mM}$ & 2700 & 1.78 & 3 & 97 \\
\hline & Average * & & & 1.35 & 75 & 25 \\
\hline
\end{tabular}

* Average toxin concentration was calculated using the data from entry 1 to 10 .

Moreover, the addition of organic phosphates, $\beta$-glycerophosphate sodium salt of 10 and $100 \mu \mathrm{M}$ each, was also investigated and no significant change was observed. Finally, Good's buffer, bicine, 
was also used to control the $\mathrm{pH}$ of the culture medium during culture. The toxin production was slightly improved compared to the control, but the cell harvest was hampered and the intracellular toxins leaked outside in harvest because of the increased viscosity of the culture.

Figure 2 indicates that approximately $140 \mu \mathrm{mol}$ of $\mathrm{C} 1 / \mathrm{C} 2$ could be produced from $100 \mathrm{~L}$ culture. It was demonstrated that over $220 \mu \mathrm{mol}$ of $\mathrm{C} 1 / \mathrm{C} 2$ was obtained from $200 \mathrm{~L}$ of the culture which was produced over 6 months cultivation. This amount of toxins would be sufficient to prepare the calibration standards of STX analogues.

\subsection{Preparation of Paralytic Shellfish Toxin Analogues}

$\mathrm{C} 1 / \mathrm{C} 2$ are one of the most modified STX analogues among the known toxins. $\mathrm{C} 1 / \mathrm{C} 2$ are also known as the lowest toxicity group among STX analogues [2]. Figure 3 shows the preparation scheme of PST analogues by chemical conversion from $\mathrm{C} 1 / \mathrm{C} 2$. $N$-sulfocarbamoyl group on $\mathrm{C} 1 / \mathrm{C} 2$ is hydrolyzed in neutral $\mathrm{pH}$, and this reaction leads $\mathrm{C} 1 / \mathrm{C} 2$ to dcGTX2/dcGTX3. Subsequently, the sulfate ester group of the toxins is reductively eliminated by 2-mercaptoethanol (2-ME) to prepare dcSTX [11]. Thus, our route to produce dcSTX is useful compared to other routes through STX [16] because production of STX is legally restricted in Japan and many countries.

Figure 3. Preparation scheme of paralytic shellfish toxin analogues. (A) Phosphate buffer (pH 7.0), $70{ }^{\circ} \mathrm{C}, 60 \mathrm{~min}$; (B) Phosphate buffer (pH 6.0), 2-mercaptoethanol, $60{ }^{\circ} \mathrm{C}, 60 \mathrm{~min}$; (C) Acetate buffer (pH 5.2), 2-mercaptoethanol, $50{ }^{\circ} \mathrm{C}, 2 \mathrm{~h}$; (D) $0.13 \mathrm{M} \mathrm{HCl}$ aq., $100{ }^{\circ} \mathrm{C}$, $15 \mathrm{~min}$; (E) 2-mercaptoethanol, $100{ }^{\circ} \mathrm{C}, 15 \mathrm{~min}$;; (F) $0.05 \mathrm{M} \mathrm{HCl}, 100{ }^{\circ} \mathrm{C}, 30 \mathrm{~min}$ [17]; (G) $7.5 \mathrm{M} \mathrm{HCl}, 100{ }^{\circ} \mathrm{C}, 3 \mathrm{~h}[18,19]$. Solid arrows, this study; dashed arrows, previous studies.

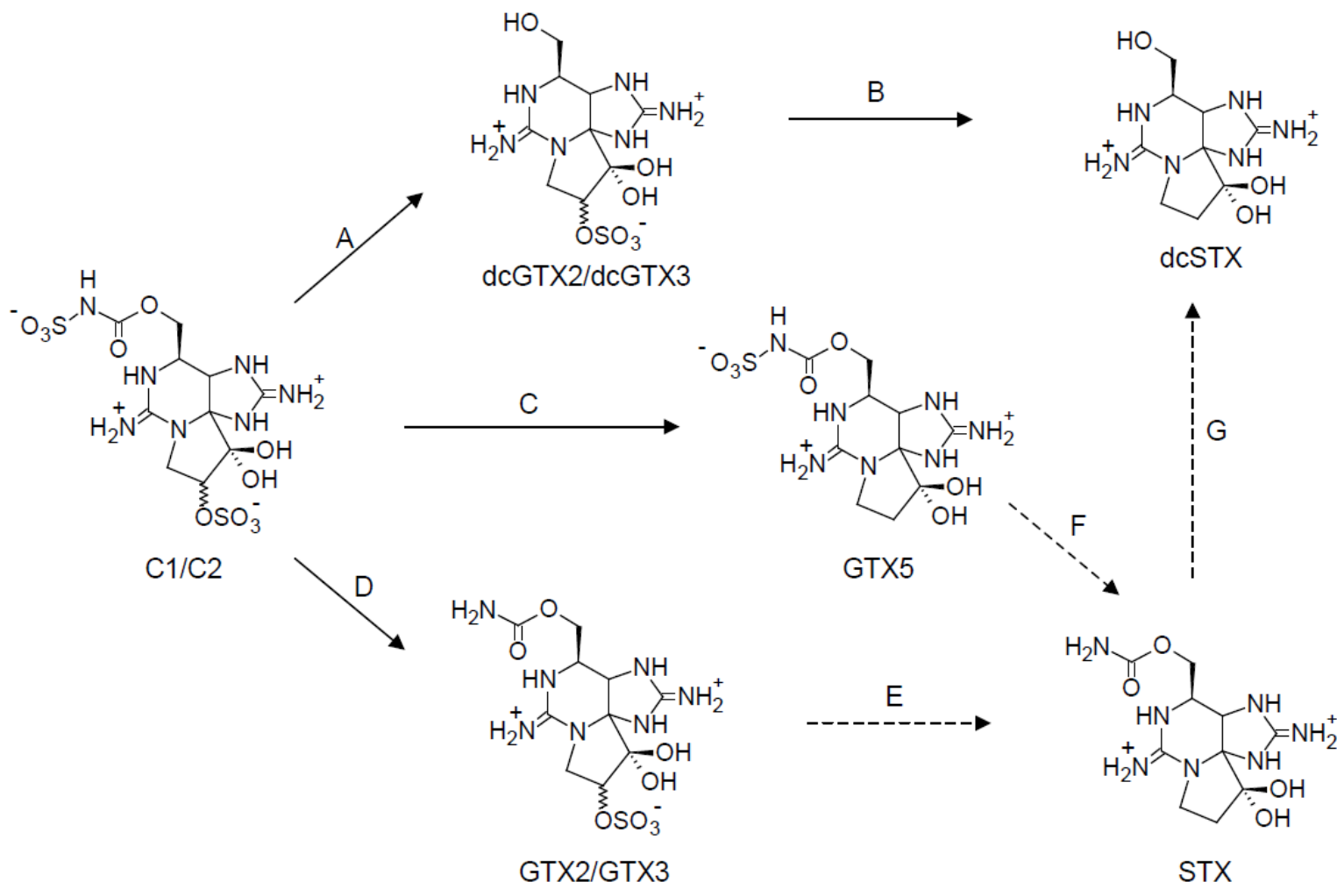


GTX5 was directly converted from $\mathrm{C} 1 / \mathrm{C} 2$ by reductive elimination of the sulfate. $\mathrm{C} 1 / \mathrm{C} 2$ were reacted with $2-\mathrm{ME}$ to give $48 \%$ of GTX5, $18 \%$ of the remaining $\mathrm{C} 1 / \mathrm{C} 2$, and $34 \%$ of unknown reactants or the loss. Of the reaction temperatures tested $\left(50-80{ }^{\circ} \mathrm{C}\right)$, a good yield $(50 \%)$ of GTX5 was obtained at $50{ }^{\circ} \mathrm{C}$. The yield reached $30 \%$ within 30 min and slowly increased with time, and then gradually declined over $3 \mathrm{~h}$. The remaining substrate was decreased to 20-40\% within 30 min and then slightly declined. HPLC analysis of the reactant mixture revealed that dcGTX2/dcGTX3 and dcSTX, as by-products in the reaction, were not produced, indicating that the reaction specifically proceeded without hydrolyzing the $N$-sulfocarbamoyl chain of $\mathrm{C} 1 / \mathrm{C} 2$. Interestingly, HPLC analysis of the reaction mixture revealed that the relative proportion of $\mathrm{C} 1$ to $\mathrm{C} 2$ decreased after the reaction, implying that the $\alpha$-epimer reacted selectively with a thiol compound compared to the $\beta$-epimer. Chromatographic behavior of the product was the same as that of the authentic GTX5 (Figure 4).

Figure 4. Chromatograms of the authentic GTX5 (upper) and the product (bottom). The authentic GTX5 was used as a mixture of GTX1-5.

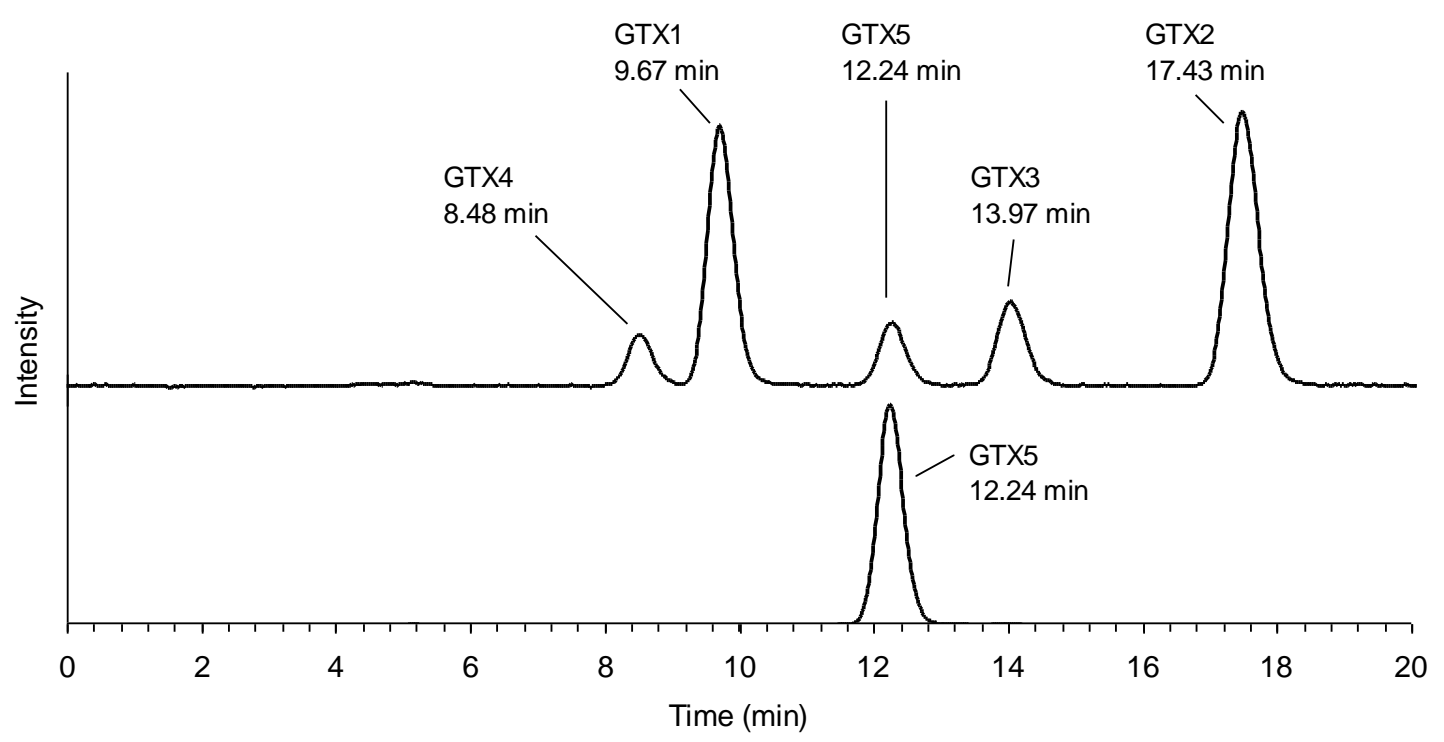

Figure 5 shows LC-MS/MS spectra of the authentic GTX5 and the product converted from C1/C2. The MS/MS spectrum of the authentic GTX5 gave ion peaks at $m / z 282$, and 300 corresponding to $\left[\mathrm{M}-\mathrm{H}_{2} \mathrm{O}-\mathrm{SO}_{3}+\mathrm{H}\right]^{+}$and $\left[\mathrm{M}-\mathrm{SO}_{3}+\mathrm{H}\right]^{+}$, respectively (Figure 5A). Basically the same fragment ions were obtained for the product (Figure 5B), demonstrating that the product was GTX5. GTX5 was prepared in $\mathrm{NaHCO}_{3}$ solution containing dithiothreitol (DTT) in a previous study [20]. They also attempted preparation of GTX5 by the reaction of C1/C2 with 2-ME in place of DTT, but GTX5 was not obtained. The fact that our method was successful to produce GTX5 with 2-ME was probably because of acidic condition in which the thioester intermediate obtained in neutral $\mathrm{pH}$ [21] was not formed. Conversion efficiency of GTX5 from C1/C2 prepared in our present method was better than that $(36 \%)$ reported in the previous study [20].

The toxins with an $N$-sulfate group such as C3/C4, GTX5 and GTX6 are easily converted to the corresponding carbamate toxins by hydrolyzing in diluted mineral acids $[12,19,22]$. In our present study, this hydrolysis reaction was applied to prepare GTX2/GTX3 from C1/C2. The products showed the same chromatographic behavior with the authentic GTX2/GTX3 in HPLC-FD. The products, 
GTX2/GTX3, were obtained as an equilibrium mixture (ratio: 3.0 to 3.5), although C1/C2 used for the reaction were not an equilibrium mixture.

Figure 5. MS/MS spectra of the authentic GTX5 (A) and the product (B). Both toxins were analyzed at declustering potential of $11 \mathrm{~V}$ and collision energy of $21 \mathrm{~V}$. The precursor ion was set to 380 .
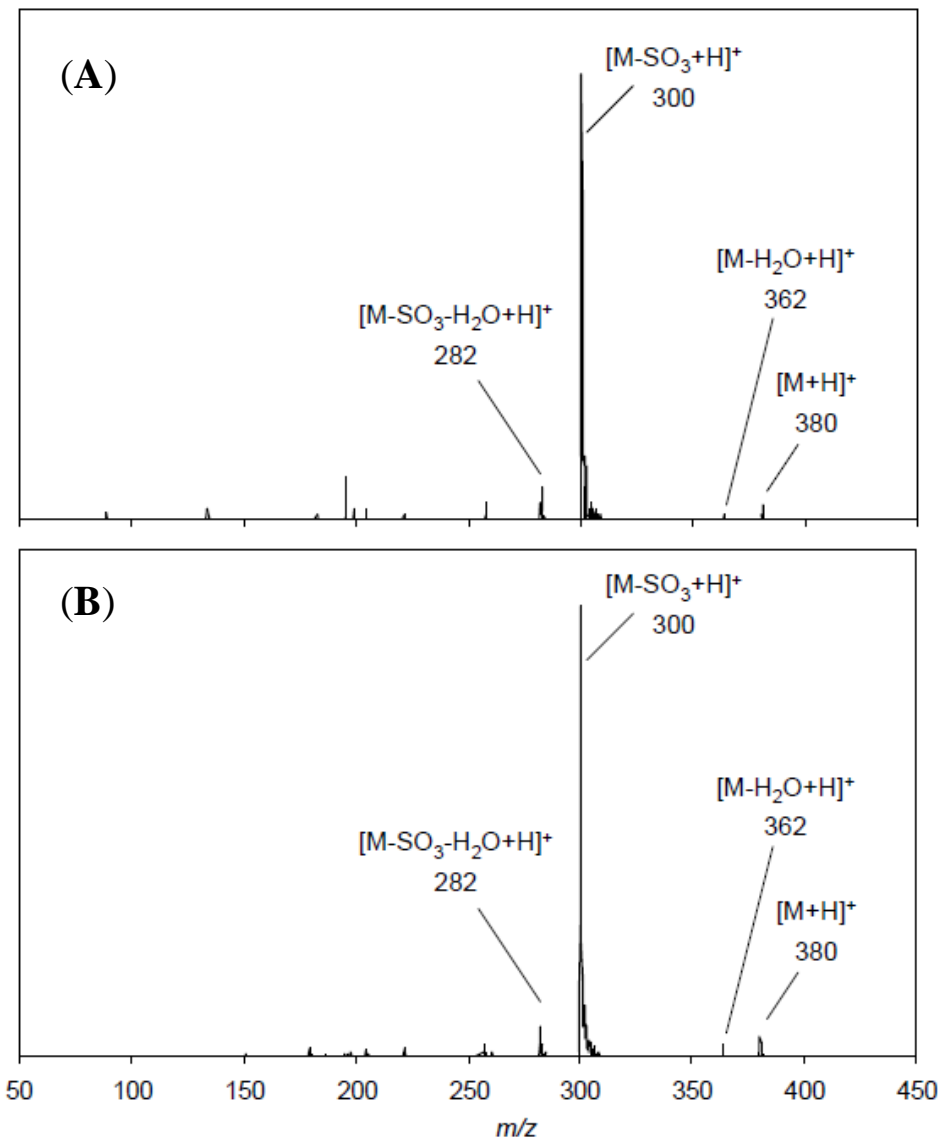

In LC-MS/MS analysis, epimers such as GTX2/GTX3 show different fragmentation patterns. GTX2 as $\alpha$-epimer gives a predominant ion peak at $m / z, 316$ corresponding to $\left[\mathrm{M}-\mathrm{SO}_{3}+\mathrm{H}\right]^{+}$, whereas GTX3 as $\beta$-epimer gives several major peaks at $\mathrm{m} / z, 298,316$ and 378 corresponding to $\left[\mathrm{M}-\mathrm{H}_{2} \mathrm{O}+\mathrm{H}\right]^{+}$. The products were confirmed to show the same fragmentation pattern in each epimer.

In the process of preparation of PST analogues, it was a requirement to avoid generation of STX because production of STX is illegal in Japan and many countries. In our method, STX was not detected in any processes by HPLC-FD. Although STX is not prepared in this study as mentioned above, STX could be prepared from GTX2/GTX3 or GTX5 as described in the previous reports [12,17], if necessary. Thus, $\mathrm{C} 1 / \mathrm{C} 2$ as starting materials could be converted to six analogues and STX, giving a relatively high yield in each reaction (Figure 3). The starting materials of C1/C2 can be obtained at a yield of $50 \%$ from the extract of the cell by purifying them with several chromatography steps such as activated charcoal, gel filtration, and ion exchange. The purified $\mathrm{C} 1 / \mathrm{C} 2$ were converted to dcGTX2/dcGTX3 (step A), GTX5 (step C), and GTX2/GTX3 (step D), and subsequently a portion of the resulting dcGTX2/dcGTX3 were converted to dcSTX (step B). At least $10 \mu$ mol of the toxin calibrants could be prepared from $200 \mathrm{~L}$ of culture of the toxic cyanobacteria (Table 2). 
Table 2. Amounts of toxins prepared from large-scale culture (200 L) of cyanobacteria A. circinalis. The amounts of $\mathrm{C} 1 / \mathrm{C} 2$ as substrates are calculated as $110 \mu \mathrm{mol}$, because the toxins are isolated at $50 \%$ yield from the extract of the cyanobacteria.

\begin{tabular}{clclccccc}
\hline $\begin{array}{c}\text { Reaction } \\
\text { steps }\end{array}$ & Substrates & $\begin{array}{c}\text { Amounts } \\
(\boldsymbol{\mu m o l})\end{array}$ & Products & $\begin{array}{c}\text { Amounts } \\
(\boldsymbol{\mu m o l})\end{array}$ & $\begin{array}{c}\text { Yields } \\
(\boldsymbol{\%})\end{array}$ & $\begin{array}{c}\text { Remaining } \\
\text { substrates }\end{array}$ & $\begin{array}{c}\text { Residual } \\
\text { Amounts } \\
(\boldsymbol{\mu m o l})\end{array}$ & $\begin{array}{c}\text { Residual } \\
\text { ratio }^{\dagger} \\
(\boldsymbol{\%})\end{array}$ \\
\hline $\mathbf{A}$ & $\mathrm{C} 1 / 2$ & 70 & $\mathrm{dcGTX} 2 / 3$ & 35 & 50 & $\mathrm{C} 1 / 2$ & 21 & 30 \\
$\mathbf{B} *$ & $\mathrm{dcGTX} 2 / 3$ & 15 & $\mathrm{dcSTX}$ & 14 & 90 & & & \\
C & $\mathrm{C} 1 / 2$ & 25 & GTX5 & 12 & 48 & $\mathrm{C} 1 / 2$ & 5 & 18 \\
$\mathbf{D}$ & $\mathrm{C} 1 / 2$ & 15 & GTX2/3 & 14 & 90 & & & \\
\hline
\end{tabular}

${ }^{\S}$ The steps correspond to Figure $3 ; *$ dcGTX2/3 were used as a part of the products in step A; ${ }^{\text {II }}$ (Amount of Product)/(Amount of Substrate $) \times 100 ;{ }^{\dagger}$ (Residual Amounts)/(Amount of Substrate $) \times 100$.

\section{Experimental Section}

\subsection{Large-Scale Culture of Cyanobacteria and the Harvest}

The cyanobacterium A. circinalis used in this study is a non-axenic strain TA04. The field sample of A. circinalis was collected at Tullaroop reservoir, Victoria, Australia, and strain TA04 was one of single-trichome isolates prepared by Negri et al. [14]. Strain TA04 was cultured in Fitzgerald medium in $2 \mathrm{~L}$ culture, and then scaled-up to $10 \mathrm{~L}$ volume (Thermo Fisher Scientific, Rochester, NY, USA). The cyanobacteria were cultured on a $16 \mathrm{~L} / 8 \mathrm{D}$ cycle at $17^{\circ} \mathrm{C}$ and $25 \mu \mathrm{mol} / \mathrm{m}^{2} / \mathrm{s}$, passing air through a disc filter $(0.20 \mu \mathrm{m}$ pore size, Advantec, Japan). The bottle cap was equipped with three pores, where one was used as air-inlet with the disc filter, one was as air-outlet with the disc filter and one was as a sampling tube with a cock. The cyanobacteria were maintained by inoculating $1 \mathrm{~L}$ of the culture in exponential growth phase (two weeks later) to $9 \mathrm{~L}$ of the sterilized medium. The $10 \mathrm{~L}$ batch culture was carried out in quintuplicate, of which one was used for inoculation of seed population, and repeated three times. Four weeks later after inoculation of the seed population, the A. circinalis cells were harvested by a continuous centrifugation or filtration (No. 2, Advantec, Japan). The cell-free culture filtrate and the cell fractions were treated according to our previous procedure [11].

\subsection{Cell Growth Measurement and Toxin Analysis}

Cell growth was estimated from fluorescent intensity derived from chlorophyll $a$ in the cell. The culture was taken in axenic through a sampling tube. Culture samples $(200 \mu \mathrm{L})$ were collected, and added to wells of a 96-well microplate in triplicate. The cell-free culture filtrate $(200 \mu \mathrm{L})$ as blank was prepared by filtering the culture with a syringe filter (Dismic-25cs, $0.45 \mu \mathrm{m}$, Advantec, Japan) or a glass fiber paper (GA-100, $25 \mathrm{~mm}$, Advantec, Japan). It is subtracted from the culture fluorescence using a fluorescence plate reader (Ex: 460 nm; Em: 645 nm, FL600, BioTek).

Toxin content $(\mathrm{C} 1 / \mathrm{C} 2)$ of the cell and the cell-free filtrate was analyzed with HPLC-FD [2]. The culture of 10 to $30 \mathrm{~mL}$ at each growth phase was passed through a glass fiber paper (GA-100, $25 \mathrm{~mm}$, Advantec, Japan) to collect cells. The paper was dissected and suspended into $1 \mathrm{~mL}$ of $0.5 \mathrm{M}$ acetic acid. The suspension was centrifuged, following ultrasonication, to obtain the supernatant as analyte. On the other hand, the filtrate was adjusted to become acidic by adding $0.5 \mathrm{M}$ acetic acid. The filtrate 
was evaporated to dryness and then dissolved in $500 \mu \mathrm{L}$ of $0.5 \mathrm{M}$ acetic acid. The toxin solution was ultrafiltered (Ultracell YM-10, 10000 MWCO, Millipore, Billerica, MA, USA) to obtain the resulting filtrate as analyte.

\subsection{Serial Preparation of $d c G T X 2 / d c G T X 3$ and $d c S T X$ from $C 1 / C 2$}

The preparation of dcGTX2/dcGTX3 and dcSTX from C1/C2 was carried out according to the method of Watanabe et al. [11]. C1/C2 as starting materials were purified from the harvested cell fraction in the cyanobacteria A. circinalis (TA04) culture. Typically, dcGTX2/dcGTX3 were obtained by the hydrolysis of $\mathrm{C} 1 / \mathrm{C} 2$. $\mathrm{C} 1 / \mathrm{C} 2$ were heated in $100 \mathrm{mM}$ potassium phosphate buffer at $\mathrm{pH} 7.0$ for $60 \mathrm{~min}$, stirring at $70{ }^{\circ} \mathrm{C}$, and then cooled on ice. The resulting dcGTX2/dcGTX3 were isolated by gel filtration chromatography (Bio Gel P-2, $10 \mathrm{~mm} \times 400 \mathrm{~mm}$, Bio-Rad) and weak-cation exchange chromatography (Bio-Rex 70, 200-400 mesh, $10 \mathrm{~mm} \times 400 \mathrm{~mm}$, Bio-Rad) at overall yield of 50\%. The purified dcGTX2/dcGTX3 was reacted under stirring conditions at $60{ }^{\circ} \mathrm{C}$ in $100 \mathrm{mM}$ potassium phosphate buffer at $\mathrm{pH} 6.0$ containing an equal volume of 2-ME for $60 \mathrm{~min}$ to quantitatively give the resulting dcSTX.

\subsection{Preparation of GTX5 from C1/C2}

$\mathrm{C} 1 / \mathrm{C} 2(1.4 \mu \mathrm{mol})$ were evaporated to dryness and dissolved in $2 \mathrm{~mL}$ of $100 \mathrm{mM}$ acetate buffer at $\mathrm{pH} 5.2$ containing equal volume of $2-\mathrm{ME}$ in a $4 \mathrm{~mL}$ glass vial. The toxin solution was reacted at $50{ }^{\circ} \mathrm{C}$ for $2 \mathrm{~h}$. The reactant was evaporated and then diluted with acetonitrile to be a final concentration of $90 \%(\mathrm{v} / \mathrm{v})$ acetonitrile solution and then the diluted solution was passed through a ZIC-HILIC cartridge (3 mL, $200 \mathrm{mg}$, Merck SeQuant, Umeå, Sweden) preconditioned with $6 \mathrm{~mL}$ of distilled water and $6 \mathrm{~mL}$ of acetonitrile in order. The cartridge was washed with $3 \mathrm{~mL}$ of acetonitrile and then eluted with $3 \mathrm{~mL}$ of distilled water as toxic fraction. The toxic fraction was purified by Bio-Rex 70 (200-400 mesh, $10 \mathrm{~mm} \times 450 \mathrm{~mm}$, Bio-Rad) to give GTX5 at an overall yield of $48 \%$. The product was confirmed and identified by the comparison with the authentic standard that was previously prepared by Oshima and confirmed in structure and purity with NMR [2]. Chromatographic behavior of the toxin was determined with HPLC-FD. The parameters on LC-MS instrument (3200 Q TRAP LC/MS/MS system, AB-SCIEX, Concord, Canada) were optimized with the authentic GTX5, prior to the analysis. The flow injection analysis was performed in mass range of $m / z, 200-500$ and positive ion mode at $500{ }^{\circ} \mathrm{C}$. The eluents were flowed at $0.2 \mathrm{~mL} / \mathrm{min}$ with $65 \% \mathrm{~B}$, where eluent $\mathrm{A}$ was distilled water and eluent $\mathrm{B}$ was acetonitrile, both containing $20 \mathrm{mM}$ formic acid. The MS/MS analysis was carried out in mass range of $m / z 50-450$ at declustering potential of $11 \mathrm{~V}$ and collision energy of $21 \mathrm{~V}$. The fragmentation pattern between the product and the authentic was compared and identified.

\subsection{Preparation of GTX2/GTX3 from C1/C2 by Acidic Hydrolysis}

Preparation of GTX2/GTX3 was carried out according to a previous method [12]. C1/C2 (1.4 $\mu$ mol) were evaporated to dryness and dissolved in $1 \mathrm{~mL}$ of $0.13 \mathrm{M} \mathrm{HCl} \mathrm{aq.} \mathrm{The} \mathrm{solution} \mathrm{was} \mathrm{heated} \mathrm{at}$ $100{ }^{\circ} \mathrm{C}$, stirring for $15 \mathrm{~min}$ and then cooled on ice. The products, GTX2/GTX3, were recovered using a 
ZIC-HILIC cartridge as described above. The reaction quantitatively proceeded. The structure was confirmed as described above.

\section{Conclusions}

In this study, major $\mathrm{N} 1-\mathrm{H}$ toxins were prepared from $\mathrm{C} 1 / \mathrm{C} 2$ as starting material. In particular, this is the first report of the detailed conditions for preparation of GTX5 from C1/C2 analogues. The chemical conversion allows us to prepare the toxins systematically. The toxin yield, of over $220 \mu \mathrm{mol}$ of $\mathrm{C} 1 / \mathrm{C} 2$ extracted from $200 \mathrm{~L}$ of culture of the cyanobacteria, was estimated to be capable of preparing at least $10 \mu \mathrm{mol}$ of each toxin, based on our reaction yields (Table 2). We previously reported a method using NMR to quantify concentrations of PST standards [23]. Based on the preparation technique of PSTs and the quantitative NMR, large amount of the N1-H toxin standards could be prepared and supplied constantly for shellfish safety monitoring programs using chemical analyses. The N1-OH toxins such as GTX1/GTX4 are also essential for the chemical analyses. The preparation technique of these toxins is currently being investigated, and will be reported elsewhere.

\section{Acknowledgements}

The authors are greatly appreciative to Blackburn, CSIRO, Australia, for providing cyanobacteria A. circinalis (TA04). This study was funded by Ministry of Health, Labour and Welfare in Japan.

\section{References}

1. Wiese, M.; D’Agostino, P.M.; Mihali, T.K.; Moffitt, M.C.; Neilan, B.A. Neurotoxic Alkaloids: Saxitoxin and Its Analogs. Mar. Drugs 2010, 8, 2185-2211.

2. Oshima, Y. Postcolumn derivatization liquid-chromatographic method for paralytic shellfish toxins. J. AOAC Int. 1995, 78, 528-532.

3. Etheridge, S.M. Paralytic shellfish poisoning: seafood safety and human health perspectives. Toxicon 2010, 56, 108-122.

4. van de Riet, J.M.; Gibbs, R.S.; Chou, F.W.; Muggah, P.M.; Rourke, W.A.; Burns, G.; Thomas, K.; Quilliam, M.A. Liquid chromatographic post-column oxidation method for analysis of paralytic shellfish toxins in mussels, clams, scallops, and oysters: single-laboratory validation. J. AOAC Int. 2009, 92, 1690-1704.

5. van Dolah, F.M.; Leighfield, T.A.; Doucette, G.J.; Bean, L.; Niedzwiadek, B.; Rawn, D.F. Single-laboratory validation of the microplate receptor binding assay for paralytic shellfish toxins in shellfish. J. AOAC Int. 2009, 92, 1705-1713.

6. Oshima, Y.; Yasumoto, T.; Kodama, M.; Ogata, T.; Fukuyo, Y.; Matuura, F. Features of paralytic shellfish poison occurring in Tohoku distinct. Bull. Jpn. Soc. Sci. Fish. 1982, 48, 525-530.

7. Goto, H.; Igarashi, T.; Sekiguchi, R.; Tanno, K.; Satake, M.; Oshima,Y.; Yasumoto, T. A Japanese project for production and distribution of shellfish toxins as calibrants for HPLC analysis. In Harmful Algae; Reguera, B., Blanco, J., Fernandez, M.L., Wyatt, T., Eds.; Xunta de Galicia and Intergovernmental Oceanographic Commission of UNESCO: Xunta de Galicia, Spain, 1998; pp. 216-219. 
8. Laycock, M.V.; Thibault, P.; Ayer, S.W.; Walter, J.A. Isolation and purification procedures for the preparation of paralytic shellfish poisoning toxin standards. Nat. Toxins 1994, 2, 175-183.

9. Thomas, K.; Blay, P.; Burton, I.W.; Cembella, A.D.; Craft, C.; Crain, S.; Hardstaff, W.R.; Laycock, M.V.; LeBlanc, D.; LeBlanc, P.; et al. Certified reference materials for marine algal toxins. In Harmful Algae 2002; Steidinger, K.A., Landsberg, J.H., Tomas, C.R., Vigo, G.A., Eds.; Florida Fish and Wildlife Conservation Commission and Intergovernmental Oceanographic Commission of UNESCO: St. Petersburg, Florida, FL, USA, 2004; pp. 216-218.

10. Oshima, Y. Chemical and enzymatic transformation of paralytic shellfish toxins in marine organisms. In Harmful Marine Algal Blooms; Lassus, P., Arzul, G., Erard, E., Gentien, P., Marcaillou, C., Eds.; Lavoisier: Paris, France, 1995; pp. 475-480.

11. Watanabe, R.; Samusawa-Saito, R.; Oshima, Y. Development of saxitoxin-conjugated affinity gels. Bioconjugate Chem. 2006, 17, 459-465.

12. Shimizu Y. Chemistry and Mechanism of Action. In Seafood and Freshwater Toxins: Pharmacology, Physiology, and Detection; Botana, L.M., Ed.; Marcel Dekker: New York, NY, USA, 2000; pp. 151-172.

13. Onodera, H.; Oshima, Y.; Watanabe, M.F.; Watanabe, M.; Bolch, C.J.; Blackburn, S.; Yasumoto, T. Screening of paralytic shellfish toxins in freshwater cyanobacteria and chemical confirmation of the toxins in cultured Anabaena circinalis from Australia. In Harmful and Toxic Algal Blooms; Yasumoto, T., Oshima, Y., Fukuyo, Y., Eds.; Intergovernmental Oceanographic Commission of UNESCO: Sendai, Japan, 1996; pp. 563-566.

14. Negri, A.P.; Jones, G.J.; Blackburn, S.I.; Oshima, Y.; Onodera, H. Effect of culture and bloom development and of sample storage on paralytic shellfish poisons in the cyanobacterium Anabaena circinalis. J. Phyrol. 1997, 33, 26-35.

15. Kellmann, R.; Neilan, B.A. Biochemical characterization of paralytic shellfish toxin biosynthesis in vitro. J. Phycol. 2007, 43, 497-508.

16. Koehn, F.E.; Ghazarossian, V.E.; Schantz, E.J.; Schnoes, H.K.; Strong, F.M. Derivatives of saxitoxin. Bioorg. Chem. 1981, 10, 412-428.

17. Harada, T.; Oshima, Y.; Yasumoto, T. Studies on paralytic shellfish poisoning in tropical waters. Part 4. Structures of two paralytic shellfish toxins, Gonyautoxins V and VI, isolated from a tropical dinoflagellate, Pyrodinium bahamense var. compressa. Agric. Biol. Chem. 1982, 46, 1861-1864.

18. Ghazarossian, V.E.; Schantz, E.J.; Schnoes, H.K.; Strong, F.M. A biologically active acid hydrolysis product of saxitoxin. Biochem. Biophys. Res. Commun. 1976, 68, 776-780.

19. Koehn, F.E.; Hall, S.; Wichmann, C.F.; Schnoes, H.K.; Reichardt, P.B. Dinoflagellate neurotoxins related to saxitoxin-structure and latent activity of toxin-B1 and toxin-B2. Tetrahedron Lett. 1982, $23,2247-2248$.

20. Laycock, M.V.; Kralovec, J.; Richards, R. Some in vitro chemical interconversions of paralytic shellfish poisoning (PSP) toxins useful in the preparation of analytical standards. J. Mar. Biotechnol. 1995, 3, 121-125.

21. Sato, S.; Sakai, R.; Kodama, M. Identification of thioether intermediates in the reductive transformation of gonyautoxins into saxitoxins by thiols. Bioorg. Med. Chem. Lett. 2000, 10, $1787-1789$. 
22. Hall, S.; Darling, S.D.; Boyer, G.L.; Reichardt, P.B.; Liue, H.W. Dinoflagellate neurotoxins related to saxitoxin: structures of toxins $\mathrm{C} 3$ and $\mathrm{C} 4$, and confirmation of the structure of neosaxitoxin. Tetrahedron Lett. 1984, 25, 3537-3538.

23. Watanabe, R.; Suzuki, T.; Oshima, Y. Development of quantitative NMR method with internal standard for the standard solutions of paralytic shellfish toxins and characterisation of gonyautoxin-5 and gonyautoxin-6. Toxicon 2010, 56, 589-595.

(C) 2011 by the authors; licensee MDPI, Basel, Switzerland. This article is an open access article distributed under the terms and conditions of the Creative Commons Attribution license (http://creativecommons.org/licenses/by/3.0/). 